\title{
Restrictive versus Liberal Blood Transfusion Strategies in Egyptian Patients with Esophageal Variceal Bleeding
}

\author{
Sherif M. Galal, Soha A. Elhawari*, Hosam M. Dawod, Ibrahim M. Ibrahim \\ Tropical Medicine Department, Faculty of Medicine, Zagazig University, Zagazig, Egypt \\ Email: "saelhawary@.zu.edu.eg
}

Received 13 April 2016; accepted 20 May 2016; published 23 May 2016

Copyright $@ 2016$ by authors and Scientific Research Publishing Inc.

This work is licensed under the Creative Commons Attribution International License (CC BY). http://creativecommons.org/licenses/by/4.0/

(c) (i) Open Access

\begin{abstract}
Background and Study Aim: Esophageal variceal bleeding is a major medical emergency and one of the most important indications for hospital admission and for blood transfusion. However, the safest and the effective blood transfusion strategy is controversial. Here, we studied the safety and the effectiveness of the restrictive versus liberal transfusion strategies in patients with esophageal variceal bleeding. Patients and Methods: The study included 342 patients with esophageal variceal bleeding. Patients were divided into 2 groups: group I (Restrictive strategy) transfusion when the hemoglobin level is $\leq 7 \mathrm{~g} / \mathrm{dl}$ and group II (Liberal strategy): transfusion when the hemoglobin level is $\leq \mathbf{9} \mathrm{g} / \mathrm{dl}$. All patients were subjected to complete blood counts, liver and kidney profiles, coagulation profile, pelvi-abdominal ultrasonography and upper GI endoscopy. Clinical outcome measures include rebleeding, infection, allergic transfusion reactions thromboembolic events, and mortality. Results: Of all patients admitted to hospital with esophageal variceal bleeding, the number of transfused RBCs units and hospital stay were more in the liberal transfusion strategy. Also, the overall rate of complications was higher in the liberal transfusion strategy $(49.7 \%$ versus $38.5 \%$ in the restrictive transfusion strategy). The most common complications were rebleeding (26.9\%) and infection (21.6\%). As regard the death rate, 13 cases $(7.6 \%)$ died in the restrictive transfusion strategy versus 25 cases $(14.6 \%)$ in the liberal transfusion one. Conclusions: For esophageal variceal bleeding, restrictive transfusion strategy is better than the liberal one as regard cost-effectiveness, risk of complications and hospital stay with no harm and less mortality as compared to liberal strategy.
\end{abstract}

\section{Keywords}

Esophageal Variceal Bleeding, Blood Transfusion, Restrictive Strategy, Liberal Strategy

\footnotetext{
${ }^{*}$ Corresponding author.
}

How to cite this paper: Galal, S.M., Elhawari, S.A., Dawod, H.M. and Ibrahim, I.M. (2016) Restrictive versus Liberal Blood Transfusion Strategies in Egyptian Patients with Esophageal Variceal Bleeding. Open Journal of Gastroenterology, 6, 151157. http://dx.doi.org/10.4236/ojgas.2016.65020 


\section{Introduction}

Esophageal variceal bleeding is a major medical emergency and one of the most important indications for hospital admission. It has a mortality rate of 20\% - 25\% [1] [2]. In Egypt, it was estimated that esophageal varices develop in about $50 \%-63 \%$ of patients with liver cirrhosis and portal hypertension [3] [4]. The strongest predictor for development of varices in cirrhosis is a hepatic venous pressure gradient (HVPG) equal or more than 10mmHg [5] [6], but variceal bleeding does not occur until the HVPG increases above $12 \mathrm{mmHg}$ [7] [8].

Acute variceal bleeding is a main indication for red blood cells (RBCs) transfusion; because acute anemia which occurs due to bleeding is associated with increased mortality. This is most likely related to impaired oxygen delivery and tissue hypoxia. The mortality rate in acute anemia is directly related to the decrease in hemoglobin. However, in some cases blood loss is not so severe, and in that condition the safest and most effective blood transfusion strategy is controversial [9] [10].

In most cases, RBCs are transfused when the hemoglobin level has decrease to a threshold at which the physician believes the risks of anemia is more than the risks of blood transfusion. This perception of the suitable level for transfusion is subjective but is influenced by multiple factors including the desire to have a safe hemoglobin level to prevent rebleeding and decrease symptoms of anemia after stoppage of bleeding [11] [12].

A restrictive transfusion strategy (RTS) was defined as transfusion(s) for GI bleeding when the hemoglobin level is less than seven grams/dl. And, a liberal transfusion strategy (LTS) was defined as transfusion(s) when hemoglobin level falls below nine grams/dl [13].

Restrictive transfusion strategy may be more effective in some situations. Experimental trials concluded that for critically ill patients, restrictive transfusion of blood is as good as liberal transfusion and more over it reduces need for blood supplies. But these trials excluded cases with gastrointestinal bleeding [14] [15]. Furthermore, several experimental and clinical studies have shown that blood transfusion can be particularly harmful in cirrhotic patients with acute variceal bleeding, since restitution of blood volume can lead to a rebound increase in portal pressure, an increase that may be prevented with somatostatin, which is associated with increasing risk of rebleeding [16]-[19].

The aim of this study was to assess the safety and the effectiveness of the restrictive versus liberal transfusion strategies in patients with esophageal variceal bleeding.

\section{Patients and Methods}

This clinical interventional study was carried out at Tropical Medicine Department, Zagazig University Hospitals, Egypt, during a period from June 2015 to November 2015. This study was approved by Ethical Committee of Faculty of Medicine, Zagazig University, including the informed consents which were obtained from all patients. There were no conflicts of interests and no funding during the study.

Patients with esophageal variceal bleeding who presented to the intensive care unit were included in the study. Patients were excluded if they refuse blood transfusion or if they have upper gastrointestinal bleeding of any cause other than esophageal varices.

According to the inclusion and the exclusion criteria, 342 patients with esophageal variceal bleeding (249 males and 93 females), their ages ranged from 34 to 65 years old (51.602 \pm 7.403$)$ were included in this study. Patients were divided into 2 groups: Group I (Restrictive Transfusion strategy-RTS): consisted of 171 patients (127 males and 44 females). Participants allocated to this group were eligible for blood transfusion when their Hb level is $\leq 7 \mathrm{~g} / \mathrm{dl}$. The objective was to maintain the Hb level between 7.1 - $9 \mathrm{~g} / \mathrm{dl}$; Group II (Liberal Transfusion strategy-LTS): consisted of 171 patients (122 males and 49 females). Participants allocated to this group were eligible for transfusion when their $\mathrm{Hb}$ level is $\leq 9 \mathrm{~g} / \mathrm{dl}$. The objective was to maintain the $\mathrm{Hb}$ level between $9.1-11 \mathrm{~g} / \mathrm{dl}$.

\section{Methods:}

Patients were subjected to:

1) Detailed history taking.

2) Thorough clinical examination.

3) Laboratory investigations (complete blood counts, liver and kidney profiles, coagulation profile).

4) Pelvi-abdominal ultrasonography and Doppler study of the portal vein (Esaote MyLab20Plus).

5) Upper GI endoscopy (PENTAX VIDEO endoscopy): endoscopy was done within 24 hours of admission. 


\section{Treatment Program:}

In both groups, hemoglobin level was measured immediately after hospital admission and every 12 hours during the first 48 hours and every 24 hours after that. Units of packed RBCs were transfused to reach the target level of $\mathrm{Hb}$.

\section{The outcome:}

The outcome include in hospital complications, number of blood units transfused and duration of hospital stay. The complications include the following (from day zero to day 14 or until patient's discharge):

1) Detection of another gastrointestinal bleeding (rebleeding).

2) Infection (This is defined as any infection necessitating a prescription for antibiotic treatment for a minimum of 5 days).

3) Blood transfusion reactions (for example, febrile transfusion reactions, allergic transfusion reaction, transfusion transmitted infections, transfusion-related acute lung injury).

4) Patients experiencing thrombo-embolic and ischemic events (myocardial ischemia or infarction, cerebrovascular stroke, pulmonary embolism, deep venous thrombosis, and acute renal failure).

5) Death rate.

\section{Statistical analysis:}

Data were checked, entered and analyzed using SPSS version 19 for data processing and statistic. Data were expressed as mean \pm SD for quantitative variable, number and percentage for qualitative one. Chi-squared $\left(\mathrm{X}^{2}\right)$ or student "t" test were used when appropriate. $\mathrm{P}<0.05$ was considered significant.

\section{Results}

In this study, no statistical significant differences were observed among both studied groups with respect to patients' age and sex (Table 1). As regard laboratory parameters in this study, WBCs were significantly more in the liberal transfusion group $(\mathrm{P}=0.00)$. While, INR level and prothrombin time were significantly more in the restrictive transfusion group ( $\mathrm{P}=0.004$ and 0.04 respectively).

According to endoscopic data of the studied groups; higher grades of O.V. (grade III and IV) $(\mathrm{P}=0.009)$ and more risky signs $(\mathrm{P}=0.013)$ were detected in the restrictive transfusion group (Table 2).

Regarding blood transfusions and hospital stay; number of RBCs units transfused was significantly more in the liberal transfusion group (the mean in group I was 1.2 versus 1.8 in group II with $\mathrm{P}=0.002$ ). While, number of fresh frozen plasma units transfused was significantly more in the restrictive transfusion group (the mean in group I was 2.5 versus 1.4 in group II with $\mathrm{P}=0.004$ ). Furthermore, patients who were under liberal transfusion strategy stayed more days at hospital (the mean in group I was 4.5 versus 5.4 in group II with $P=0.002$ ) (Table 3).

Concerning the study outcome as shown in Table 4 and Figure 1, the overall rate of complications was statistically significant higher in the liberal transfusion group (49.7\% versus $38.5 \%$ in the restrictive transfusion group) $(P=0.03)$. Cardiac complications, stroke and TIA, acute kidney injury and allergic reactions due to blood component were comparable in both groups. While the rates of rebleeding and infection were statistically significant higher in the liberal transfusion group (26.9\%, $\mathrm{P}=0.03$ and $21.6 \%, \mathrm{P}=0.005$ respectively). As regard the death rate, there was statistically significant difference between both studied groups $(\mathrm{P}=0.03)$. Thirteen cases $(7.6 \%)$ died in the restrictive transfusion group versus 25 cases (14.6\%) in the liberal transfusion one.

Table 1. Baseline characteristics among both studied groups.

\begin{tabular}{|c|c|c|c|c|c|c|}
\hline & \multicolumn{2}{|c|}{$\begin{array}{c}\text { Group I } \\
\text { (RTS) } \\
(\mathbf{n}=171)\end{array}$} & \multicolumn{2}{|c|}{$\begin{array}{c}\text { Group II } \\
\text { (LTS) } \\
(\mathrm{n}=171)\end{array}$} & $\mathbf{t}$ & $\mathbf{P}$ \\
\hline Mean \pm SD & \multicolumn{2}{|c|}{$51.47 \pm 8.81$} & \multicolumn{2}{|c|}{$51.17 \pm 8.10$} & 0.332 & 0.740 \\
\hline & No. & $\%$ & No. & $\%$ & $X^{2}$ & $\mathbf{P}$ \\
\hline \multicolumn{7}{|l|}{ Gender } \\
\hline Male & 127 & 74.3 & 122 & 71.3 & 0.36 & 0.54 \\
\hline Female & 44 & 25.7 & 49 & 28.7 & & \\
\hline
\end{tabular}


Table 2. Endoscopic data among both studied groups.

\begin{tabular}{|c|c|c|c|c|c|c|c|c|}
\hline & & & \multicolumn{2}{|c|}{$\begin{array}{c}\text { Group I } \\
\text { (RTS) } \\
(\mathbf{n}=171)\end{array}$} & \multicolumn{2}{|c|}{$\begin{array}{c}\text { Group II } \\
\text { (LTS) } \\
(\mathbf{n}=171)\end{array}$} & \multirow[t]{2}{*}{$X^{2}$} & \multirow[t]{2}{*}{$\mathbf{P}$} \\
\hline & & & No & $\%$ & No & $\%$ & & \\
\hline \multirow{6}{*}{ Endoscopic findings } & \multirow{4}{*}{ O.V. grades } & Grade I & 17 & 9.9 & 8 & 4.7 & \multirow{4}{*}{11.6} & \multirow{4}{*}{$0.009^{*}$} \\
\hline & & Grade II & 116 & 67.8 & 143 & 83.6 & & \\
\hline & & Grade III & 33 & 19.3 & 17 & 9.9 & & \\
\hline & & Grade IV & 5 & 2.9 & 3 & 1.8 & & \\
\hline & \multirow{2}{*}{ O.V. risky signs } & No & 118 & 69.0 & 138 & 80.7 & \multirow{2}{*}{6.21} & \multirow[t]{2}{*}{$0.013^{*}$} \\
\hline & & Yes & 53 & 31.0 & 33 & 19.3 & & \\
\hline
\end{tabular}

$* \mathrm{P}<0.05$ is significant.

Table 3. Blood transfusions and duration of hospital stay among both studied groups.

\begin{tabular}{|c|c|c|c|c|}
\hline & $\begin{array}{c}\text { Group I } \\
\text { (RTS) } \\
(\mathrm{n}=171)\end{array}$ & $\begin{array}{c}\text { Group II } \\
\text { (LTS) } \\
(\mathrm{n}=171)\end{array}$ & \multirow[t]{2}{*}{$\mathbf{t}$} & \multirow[t]{2}{*}{$\mathbf{P}$} \\
\hline & Mean \pm SD & Mean \pm SD & & \\
\hline Units of RBCs transfused & $1.2 \pm 1.480$ & $1.8 \pm 1.743$ & -3.110 & $0.002 *$ \\
\hline Units of fresh frozen plasma transfused & $2.5 \pm 4.068$ & $1.4 \pm 3.121$ & 2.878 & $0.004 *$ \\
\hline Duration of hospital stay & $4.5 \pm 1.840$ & $5.4 \pm 2.989$ & -3.137 & $0.002 *$ \\
\hline
\end{tabular}

$* \mathrm{P}<0.05$ is significant.

Table 4. The study outcome among both studied groups.

\begin{tabular}{|c|c|c|c|c|c|c|}
\hline \multirow[t]{2}{*}{ Outcome } & \multicolumn{2}{|c|}{$\begin{array}{c}\text { Group I } \\
\text { (RTS) } \\
(\mathbf{n}=171)\end{array}$} & \multicolumn{2}{|c|}{$\begin{array}{c}\text { Group II } \\
\text { (LTS) } \\
(\mathbf{n}=171)\end{array}$} & \multirow[t]{2}{*}{$X^{2}$} & \multirow[t]{2}{*}{$\mathbf{P}$} \\
\hline & No & $\%$ & No & $\%$ & & \\
\hline Overall rate of complications & 66 & 38.5 & 85 & 49.7 & 4.28 & $0.03 *$ \\
\hline Rebleeding & 30 & 17.5 & 46 & 26.9 & 4.33 & $0.03^{*}$ \\
\hline Infection & 18 & 10.5 & 37 & 21.6 & 7.82 & $0.005^{*}$ \\
\hline Cardiac complications & 0 & 0.0 & 3 & 1.8 & 3.02 & 0.08 \\
\hline Stroke and TIA & 2 & 1.2 & 3 & 1.8 & 0.203 & 0.65 \\
\hline Acute kidney injury & 12 & 7.0 & 12 & 7.0 & 0.00 & 1.00 \\
\hline Allergic reactions & 14 & 8.2 & 19 & 11.1 & 0.83 & 0.36 \\
\hline Death rate & 13 & 7.6 & 25 & 14.6 & 4.26 & $0.03^{*}$ \\
\hline
\end{tabular}

$* \mathrm{P}<0.05$ is significant.

\section{Discussion}

Acute variceal bleeding (AVB) is the most common cause of acute upper gastrointestinal bleeding (AUGIB) in patients with cirrhosis [20]. Current RBCs transfusion concepts in AUGIB depend on consensus opinion. The international guideline recommends transfusion when the hemoglobin is $\leq 7 \mathrm{gm} / \mathrm{dl}$ [10]. For those with AUGIB due to portal hypertension, guidelines recommend keeping the hemoglobin level around 8 gm/dl [21]. In this study, two transfusion strategies were compared; the restrictive transfusion strategy in which the hemoglobin threshold for transfusion was $\leq 7 \mathrm{~g} / \mathrm{dl}$, with a target range to maintain the hemoglobin level between 7.1 - 9 g/dl; and the liberal transfusion strategy in which the hemoglobin threshold for transfusion was $\leq 9 \mathrm{~g} / \mathrm{dl}$, with a target range to maintain the hemoglobin level between $9.1-11 \mathrm{~g} / \mathrm{dl}$.

The present study showed statistically significant increase in number of RBCs units transfused in LTS group (mean $=1.8$ vs. 1.2 in the RTS group, $\mathrm{P}=0.002$ ). This is consistent with Villanueva and his colleagues which showed significantly more RBCs units transfused in LTS group (mean $=3.7)$ than RTS group $($ mean $=1.5)(P=$ 


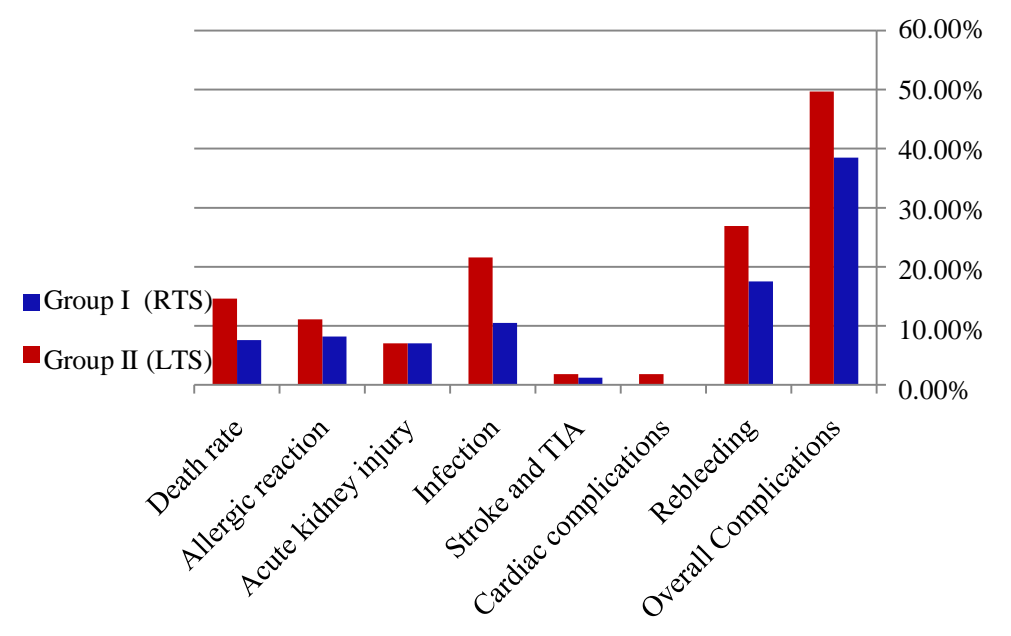

Figure 1. Study outcomes from the studied groups.

0.01) [13]. On the other hand, this study revealed that the number of plasma units transfused was significantly higher in RTS group (mean $=2.5$ vs. 1.4 in LTS group, $\mathrm{P}=0.004$ ). These results are in disagreement with Villanueva et al. which had more plasma units transfused in the LTS group (41 units of plasma transfused vs. 28 in the RTS group, $\mathrm{P}=0.13$ ). This disagreement may be attributed to the higher INR level of RTS group in this study (mean $=2.2$ vs. 1.4 in the LTS group, $\mathrm{P}=0.004$ ) [13].

As regard complications, it was found that the overall rate of complications was higher in the LTS group (49.7\% of LTS group vs. 38.5\% of RTS group), with statistically significant difference between both groups ( $\mathrm{P}=0.03$ ). These results are in agreement with Al-Jaghbeer and Yende [22], and Villanueva et al. [13]. Both studies rated more complications in the LTS group ( $48 \%$ of LTS group vs. $40 \%$ of RTS group, $\mathrm{P}=0.02$ ).

Previous studies reported more rebleeding in patients of LTS group; 16\% of LTS group vs 10\% of RTS group, $\mathrm{P}=0.01$ [22] and $22 \%$ of LTS group vs. $11 \%$ of RTS group, $\mathrm{P}=0.05$ [13]. Our results, which are consistent with the results from those studies, showed that despite the presence of more cases with larger varices (grade III, 19.3\% and grade IV, 2.9\%) and more risky signs (31.0\%) in the RTS group, rebleeding occurred more with LTS group (26.9\% of LTS group vs. $17.5 \%$ of RTS group, $\mathrm{P}=0.03$ ). This may be related to excessive RBCs transfusion which is likely increase portal pressure through volume overload, in patients of liver cirrhosis and bleeding esophageal varices, with increasing the risk of rebleeding [13] [17]. Also, Transfusion may counteract the splanchnic vasoconstrictive response caused by hypovolemia, inducing an increase in splanchnic blood flow and pressure that may impair the formation of clots [23] [24].

As regard hospital stay, it was found that patients of LTS group stayed more days at hospital (mean $=5.4$ ) than patients of RTS group (mean $=4.5)$ with statistically significant difference $(P=0.002)$. These results are in agreement with Villanueva and his colleagues which showed more hospital stay in LTS group $(P=0.01)$. This result may be due to higher rate of complications, especially rebleeding, in the LTS group [13]. Furthermore, it was found that infection was significantly higher $(\mathrm{P}=0.005)$ in LTS group $(21.6 \%)$ than in RTS group (10.5\%) which may be attributed to more hospital stay in the LTS group which makes the patient at more risk for hospital acquired infection.

Also, this study showed that the death rate was more in LTS group (14.6\% in LTS vs. $7.6 \%$ in RTS), with statistically significant difference between the two groups $(\mathrm{P}=0.03)$. These results are consistent with results from previous studies performed in other settings, which found that a restrictive transfusion strategy did not increase [15] [25] and even decreased [14] [26] the mortality observed with a liberal transfusion strategy. Moreover, these findings are in agreement with the findings of Villanueva et al. in which all patients with cirrhosis had lower risk of death in the RTS group than the LTS group [13]. Similar results were obtained by Al-Jaghbeer and Yende which concluded that probability of survival at 6 weeks was higher in the RTS group than in the LTS group (95\% versus 91\%) $(\mathrm{P}=0.02)$ [22]. These results may be related to lower rate of serious complications in RTS group, such as infection and rebleeding, which need urgent therapy.

From the present study and its results, we can summarize that the outcome among patients with esophageal variceal bleeding is better with a restrictive transfusion strategy, as compared with a liberal transfusion strategy. 


\section{Conclusion}

For esophageal variceal bleeding, restrictive transfusion strategy is better than the liberal one as regard cost-effectiveness, risk of complications and hospital stay with no harm and less mortality as compared to liberal strategy.

\section{References}

[1] Graham, D.Y. and Smith, J.L. (1981) The Course of Patients after Variceal Hemorrhage. Gastroenterology, 80, 800809.

[2] Burroughs, A.K., Mezzanotte, G., Phillips, A., McCormick, P.A. and McIntyre, N. (1989) Cirrhotics with Variceal Hemorrhage: The Importance of the Time Interval between Admission and the Start of Analysis for Survival and Rebleeding Rates. Hepatology, 9, 801-807. http://dx.doi.org/10.1002/hep.1840090602

[3] Hunter, M.S., El-Banna, E.A. and El-Behiry, N.M. (1989) A Study of the Relation of the Liver Pathology to Oesophagealvarices and Upper Gastrointestinal Bleeding in Endemic Hepatosplenomegaly. New Egyptian Journal of Medicine, 3, 1535-1540.

[4] El-Kady, N., El-Boraey, Y.A. and Hamza, I. (2000) Clinical, Endoscopic and Doppler Assessment of Patients on Long-Term Injection Sclerotherapy for Oesophageal Varices. Medical Journal Cairo University, 1, 63-99.

[5] Groszmann, R.J. (1993) Hyperdynamic State in Chronic Liver Diseases. Journal of Hepatology, 17, S38-S40. http://dx.doi.org/10.1016/S0168-8278(05)80454-4

[6] Ripoll, C., Groszmann, R., Garcia-Tsao, G., Grace, N., Burroughs, A., Planas, R., et al. (2007) Hepatic Venous Pressure Gardient Predicts Clinical Descompensation in Patients with Compensated Cirrhosis. Gastroenterology, 133, 481488. http://dx.doi.org/10.1053/j.gastro.2007.05.024

[7] Groszmann, R.J., Bosch, J., Grace, N.D., Conn, H.O., Garcia-Tsao, G., Navasa, M., et al. (1990) Hemodynamic Events in a Prospective Randomized Trial of Propranolol versus Placebo in the Prevention of a First Variceal Hemorrhage. Gastroenterology, 99, 1401-1407.

[8] Feu, F., García-Pagán, J.C., Bosch, J., Luca, A., Terés, J., Escorsell, A., et al. (1995) Relation between Portal Pressure Response to Pharmacotherapy and Risk of Recurrent Variceal Haemorrhage in Patients with Cirrhosis. Lancet, 346, 1056-1059. http://dx.doi.org/10.1016/S0140-6736(95)91740-3

[9] Barkun, A., Bardou, M. and Marshall, J.K. (2003) Consensus Recommendations for Managing Patients with Nonvariceal Upper Gastrointestinal Bleeding. Annals of Internal Medicine, 139, 843-857. http://dx.doi.org/10.7326/0003-4819-139-10-200311180-00012

[10] Barkun, A.N., Bardou, M., Kuipers, E.J., Sung, J., Hunt, R.H., Martel, M., et al. (2010) International Consensus Recommendations on the Management of Patients with Nonvariceal Upper Gastrointestinal Bleeding. Annals of Internal Medicine, 152, 101-113. http://dx.doi.org/10.7326/0003-4819-152-2-201001190-00009

[11] UK Comparative Audit of Upper Gastrointestinal Bleeding and the Use of Blood (2007) British Society of Gastroenterology. www.bsg.org.uk/pdf_word_docs/blood_audit_report_07.pdf

[12] Jairath, V., Kahan, B.C., Gray, A., Doré, C.J., Mora, A., Dyer, C., et al. (2013) Restrictive vs Liberal Blood Transfusion for Acute Upper Gastrointestinal Bleeding: Rationale and Protocol for a Cluster Randomized Feasibility Trial. Transfusion Medicine Reviews, 27, 146-153. http://dx.doi.org/10.1016/j.tmrv.2013.04.001

[13] Villanueva, C., Colomo, A., Bosch, A., Concepción, M., Hernandez-Gea, V., Aracil, C., et al. (2013) Transfusion Strategies for Acute Upper Gastrointestinal Bleeding. New England Journal of Medicine, 368, 11-21. http://dx.doi.org/10.1056/NEJMoa1211801

[14] Hébert, P.C., Wells, G., Blajchman, M.A., Marshall, J., Martin, C., Pagliarello, G., et al. (1999) A Multicenter, Randomized, Controlled Clinical Trial of Transfusion Requirements in Critical Care. New England Journal of Medicine, 340, 409-417. http://dx.doi.org/10.1056/NEJM199902113400601

[15] Lacroix, J., Hébert, P.C., Hutchison, J.S., Hume, H.A., Tucci, M., Ducruet, T., et al. (2007) Transfusion Strategies for Patients in Pediatric Intensive Care Units. New England Journal of Medicine, 356, 1609-1619. http://dx.doi.org/10.1056/NEJMoa066240

[16] Kravetz, D., Sikuler, E. and Groszmann, R.J. (1986) Splanchnic and Systemic Hemodynamics in Portal Hypertensive Rats during Hemorrhage and Blood Volume Restitution. Gastroenterology, 90, 1232-1240.

[17] McCormick, P.A., Jenkins, S.A., McIntyre, N. and Burroughs, A.K. (1995) Why Portal Hypertensive Varices Bleed and Bleed: A Hypothesis. Gut, 36, 100-103. http://dx.doi.org/10.1136/gut.36.1.100

[18] Castaneda, B., Morales, J., Lionetti, R., Moitinho, E., Andreu, V., Pérez-Del-Pulgar, S., et al. (2001) Effects of Blood Volume Restitution Following a Portal Hypertensive-Related Bleeding in Anesthetized Cirrhotic Rats. Hepatology, 33, 
821-825. http://dx.doi.org/10.1053/jhep.2001.23437

[19] Villanueva, C., Ortiz, J., Minana, J., Soriano, G., Sàbat, M., Boadas, J., et al. (2001) Somatostatin Treatment and Risk Stratification by Continuous Portal Pressure Monitoring during Acute Variceal Bleeding. Gastroenterology, 121, 110117. http://dx.doi.org/10.1053/gast.2001.25536

[20] Herrera, J.L. (2014) Management of Acute Variceal Bleeding. Clinical Liver Disease, 18, 347-357. http://dx.doi.org/10.1016/j.cld.2014.01.001

[21] De Franchis, R. (2010) Revising Consensus in Portal Hypertension: Report of the Baveno V Consensus Workshop on Methodology of Diagnosis and Therapy in Portal Hypertension. Journal of Hepatology, 53, 762-768. http://dx.doi.org/10.1016/j.jhep.2010.06.004

[22] Al-Jaghbeer, M. and Yende, S. (2013) Blood Transfusion for Upper Gastrointestinal Bleeding: Is Less More again? Critical Care, 17, 325. http://dx.doi.org/10.1186/cc13020

[23] Roberts, I., Evans, P., Bunn, F., Kwan, I. and Crowhurst, E. (2001) Is the Normalization of Blood Pressure in Bleeding Trauma Patients Harmful? Lancet, 357, 385-387. http://dx.doi.org/10.1016/S0140-6736(00)03653-9

[24] Duggan, J.M. (2001) Transfusion in Gastrointestinal Hemorrhage-If, When and How Much? Alimentary Pharmacology \& Therapeutics, 15, 1109-1113. http://dx.doi.org/10.1046/j.1365-2036.2001.01013.x

[25] Carson, J.L., Terrin, M.L., Noveck, H., Sanders, D.W., Chaitman, B.R., Rhoads, G.G., et al. (2011) Liberal or Restrictive Transfusion in High Risk Patients after Hip Surgery. New England Journal of Medicine, 365, 2453-2462. http://dx.doi.org/10.1056/NEJMoa1012452

[26] Marik, P.E. and Corwin, H.L. (2008) Efficacy of Red Cell Transfusion in the Critically Ill: A Systematic Review of the Literature. Critical Care Medicine, 36, 2667-2674. http://dx.doi.org/10.1097/CCM.0b013e3181844677 